\title{
42. COMMISSION DES ETOILES DOUBLES PHOTOMETRIQUES
}

\section{Report of Meetings}

Presidents: J. E. Merrill, V. P. Tseslvich.

SECRETARY: A. H. Batten.

\section{Business and Administrative Sessions}

Business and administrative sessions were held on 27 August (intervals $a$ and $b$ ) and on 3r August (interval $a$ ). Dr Tsesevich presided at the second session, Dr Merrill at the first and third. The average attendance at each session was about 60 . No scientific sessions were held by the Commission alone; it co-sponsored the Joint Discussion on Close Binaries.

Dr Merrill announced the appointment of Dr Batten as Recording Secretary for the sessions and of Drs Fracastoro, O'Connell and Tsesevich as interpreters in case of need.

The members standing, Dr Sahade read the following tribute to the memory of Otto Struve:

'Our Commission and the Union lost last year one of the most significant scientists of our time, an enthusiastic astronomer who felt such a passion for our science that he devoted his time fully to achieve its advancement by every possible means. Otto Struve was an observational astronomer who loved to be at the telescope, to get spectra, to interpret them. Though his interest in astronomy was very broad he felt especially attracted by the field of close binary systems and his inspiration has for years been a major factor in the furthering of our understanding of the kind of stars that are within the domain of our Commission. The resulting advances have been enormous, as we all know!

'It seems appropriate to stress at this time the encouragement and inspiration we have gained from Prof. Struve and the responsibility that this implies. I feel sure that if we live up to this responsibility we shall be paying Prof. Struve the kind of tribute he would have liked most.'

The President stated that this resolution would also be presented at the Joint Discussion on Close Binaries and that copies would be sent to the Executive Committee and to Mrs Struve.

On motion of Dr Plavec the following resolutions were adopted:

I. 'The Commission believes that the publication of the Eclipsing Binary Circulars should be continued because of their usefulness both to observers and to theoretical workers. Therefore the Commission asks the editor, Dr K. Kordylewski, to continue the publication of these Circulars.'

2. 'The Commission asks the Union to make a grant of U.S. \$10o to Dr Kordylewski, to be applied by him towards the cost of publishing the Eclipsing Binary Circulars.'

In reply to a question from the floor Dr Kordylewski explained that the amount requested was token support and that other funds would be available.

On motion by Dr O'Connell there were adopted two resolutions concerning the proposed Third Bamberg Symposium on Variable Stars, similar to two resolutions which Commission 27 had already adopted:

I. 'Commission 42 welcomes the intention of Prof. Strohmeier of the Bamberg Observatory to organize a third symposium on variable stars, in 1965 and, subject to his wishes, stands ready to assist in the preparations for the Symposium.'

2. 'The Commission requests that the Union make a token grant of U.S. $\$ 500$ to Prof. 
Strohmeier, which would enable him to invite one or more astronomers from very distant countries to attend the Symposium.'

Dr O'Connell was appointed to represent Commission 42 on the Organizing Committee of the Symposium.

Dr Merrill expressed his appreciation of the help he received from Drs O'Connell, Tsesevich and Wood in the preparation of the Draft Report. He then called for discussion of the Report in general, on the understanding that notes on matters such as typographical changes would be handed to Mrs Merrill before the end of the Assembly. Dr Popper drew attention to the great service to the field of eclipsing binaries represented by the bibliography contained in the Report. Dr Plavec suggested that fuller details be given of observations still in progress if and when it was practicable to do so; Dr Fracastoro suggested that a clearer separation between published and unpublished work might help in this respect. On motion of Dr Popper the Draft Report was approved, including such minor changes as would later be incorporated. In view of this thorough discussion, the Commission felt it unnecessary to set up the ad hoc committee to consider changes in the form of the Draft Report which had been provided for in the agenda.

\section{REPORTS OF STANDING COMMITTEES}

I. Times of Minima. Dr Kopal stated that he had nothing to report and that, because of his many other commitments, he was unable to devote to this committee the time it deserved. He asked the Commission to relieve him of these duties and suggested that Dr Plavec be asked to take up the work. Dr Plavec was immediately elected Chairman of the committee by acclamation.

2. Russell Memorial Volume. Dr Merrill, reporting for this committee, stated that extensive discussions with Drs Spitzer and Schwarzschild in Princeton had resulted in the regretful conclusion that the production in the near future of a memorial volume to Henry Norris Russell appeared to present insuperable difficulties. The possibility remained of commemorating the centenary of his birth in some suitable way, but in the meantime the existing committee should be discontinued. The Commission concurred.

3. Use of Artificial Satellites. Dr Kopal stated that there was not yet anything to report, but he had hopes that in the foreseeable future there might be an opportunity for observations of eclipsing binaries to be made outside the Earth's atmosphere. He recommended that the committee be continued, to watch over the interests of the Commission in this respect, and the Commission so voted.

4. Co-ordinated Programs. Dr Wood, Chairman, reported on the programs undertaken at Berkeley, as follows.

AW Pegasi. The co-ordinator, Dr Tsesevich, found that the system was not as suitable for international work as had been supposed. The campaign was therefore not undertaken.

$W$ Serpentis. Five observatories made photo-electric observations and three made spectrographic observations. The co-ordinator, Dr Sahade, felt, however, that the response was not sufficient for a full co-ordinated program.

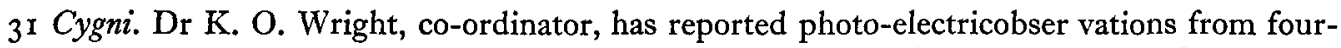
teen observatories and spectrographic observations from seven. It is a problem to find time to discuss the photometric observations.

$\zeta$ Aurigae. Dr Gyldenkerne, co-ordinator, also reported a successful campaign. A grant from the American Philosophical Society had made possible the distribution of uniform sets of color filters. Standardization of color systems was particularly important for this star, in which large color changes take place during eclipse. Even these standard filters (which Dr O'Connell 
had tested and calibrated) should still be calibrated by observers on their own equipment. The observations were not yet reduced, but useful results were expected.

For new co-ordinated programs the committee suggested the following systems and coordinators: W Serpentis (Dr Sahade) and SX Cassiopeiae (Dr Koch). In both cases the program was to be undertaken only if the co-ordinator felt the response to the initial appeal was sufficient to justify a full program. Because of the length of the period of SX Cas the committee suggested that the system be observed whenever available for the next three years, with the observers concentrating especially on the minima and shoulders but also giving as much attention as they can to observations between eclipses.

The committee felt that the photometric patrol proposed by Dr Batten for U Coronae Borealis was desirable but could best be undertaken by interested amateurs, under the guidance of Dr Batten; it recommends that he continue his own spectrographic patrol of the star. The system of $\beta$ Lyrae also merited such treament. Finally, the committee called attention to the need for continued observations, both in and out of eclipse, on 31 and 32 Cygni and $\zeta$ Aurigae.

The report was approved.

Dr Martynov called attention to the large number of eclipsing binaries with spectrographic orbits but no good photometric observations which he had found during the compilation of his Bibliography of Spectroscopic Binaries.

5. Times of Minima and Period Changes. Dr Plavec, the new Chairman, proposed the selection of about 20 systems to be watched for period changes. Individual observers would be asked to assume responsibility for determining photo-electrically one minimum for each of two systems each year. Thus, in time, a large body of information would be accumulated.

In discussion the need for observing secondary minima was mentioned. Dr Popper pointed out the need felt by spectrographic observers for accurate phases. Dr Herczeg suggested inclusion of some W Ursae Majoris systems in spite of the distortions well known to be present in their light curves.

The committee's proposal was approved, with the decisions on details left to Dr Plavec and his committee. The exact composition of the committee for $1964-7$ will be considered by the Organizing Committee in the near future.

\section{FUTURE ORGANIZATION OF THE COMMISSION}

Dr Merrill announced that in accordance with the decision of the Executive Committee he and Dr Tsesevich would continue in their respective offices of President and Vice-President. He requested that, in view of the increasing work-load, the Organizing Committee be augmented to six members (in addition to the President and Vice-President). This proposal was accepted. Dr Kopal announced his wish to resign from the Committee, pointing out that he had been closely associated with the direction of the Commission ever since its inception. The appointment by the President of Drs Larsson-Leander, O'Connell, Plavec, Schneller, Wood and K. O. Wright as the Organizing Committee for $1964-7$, was received with acclamation.

The President recalled the proposal of Dr Plaut at Berkeley that there be a single Commission for all binary stars. He described a proposal made by Drs Petrie, Wright and Batten which the Organizing Committee $(196 \mathrm{I}-4)$ felt would be a significant step in increasing co-operation among students of the different types of binary systems. He then proposed that Commission 42 request Commissions 26 and 30 to set up with this Commission joint working-groups which would draw the attention of the three Commissions to matters of common interest and promote the co-operation needed in pursuing them. Commission $3^{\circ}$ had agreed to the formation of a 
joint 30-42 group; the President of Commission 26 was in agreement with the proposal to form a joint 26-42 group, and would discuss it with his Organizing Committee.

Commission 42 approved the formation of such groups, and some suggestions for membership were made for consideration by the Organizing Committees concerned. It is assumed that the preparation of lists of binaries in need of observation will now be a responsibility of the appropriate Joint Group.

\section{BIBLIOGRAPHY}

Dr Merrill suggested that the Commission undertake a full appraisal of the usefulness of the Bibliography which it was now producing regularly. He pointed out the amount of work this involved for the contributors and the distributors, but suggested that this was at least partly offset by the saving of time in the preparation of the Draft Report. There was a clear agreement that this Bibliography should be continued; alternative arrangements (such as co-operation with the Bulletin Signalétique) did not seem to hold promise either of reduction in work or increase in the speed of production. Dr Martynov suggested that consideration be given to the practicability of preparing an index to the Bibliography periodically.

The problems of the Bibliography were further discussed by an ad hoc committee of the Contributors. Its Chairman, Mrs Kron, reported that this committee recommended that the Bibliography be continued in substantially its present form and that the next issue be circulated in March 1965.

The following will serve as Contributors:

$\begin{array}{ll}\text { Dr Hardie and Dr Sahade } & \text { The Americas and southern hemisphere } \\ \text { Dr Fracastoro } & \text { Italy } \\ \text { Dr Schneller } & \text { Germany } \\ \text { Dr Plavec } & \text { Czechoslovakia and Poland } \\ \text { Dr Shulberg } & \text { U.S.S.R. } \\ \text { Dr Sinvhal } & \text { India and Indonesia } \\ \text { Dr Kitamura } & \text { Japan } \\ \text { Dr Kwee } & \text { other European countries }\end{array}$

MEMBERSHIP

The President raised the question of criteria for membership on the Commission. The Commission felt no discussion was at present necessary.

\section{RESOLUTIONS}

The following resolutions were approved; the name of the mover is shown in brackets.

I. That the President send to Dr and Mrs Shapley a letter conveying the greetings of the Commission and its regret at their absence. (Dr Witkowski)

2. The Commission notes with appreciation the publication by the Leander McCormick Observatory of an extensive list of spectral types of eclipsing binaries. It is hoped that the Observatory will find it possible to continue this very valuable work. (Dr O'Connell)

3. The Commission calls the attention of all workers engaged in studying stellar variations, to the enormous amount of material still available in the plate collection of the Harvard College Observatory, and recommends more extensive use of this source of information. (Dr Tsesevich)

4. The Commission requests the Academy of Sciences of the Ukrainian Republic to publish as soon as practicable the 'Atlas of Finding Charts for Variable Stars' prepared by Dr Tsesevich and Dr Kazagmas. (Dr Merrill) 
5. The Commission notes with satisfaction the establishment of new observatories in the southern hemisphere, and calls attention to the importance of increased activity in all phases of work on eclipsing binaries at various longitudes in the southern hemisphere. (Dr O'Comell)

6. The Commission wishes to record its appreciation to Dr Batten for compiling his list of eclipsing binaries in need of spectrographic observation. (Dr Hogg)

7. Commission 42 endorses the work of Prof. Martynov on his Bibliography of Spectroscopic Binary Orbits and congratulates him on the completion of the fourth volume. The Commission hopes that Prof. Martynov will continue to collect this information and make it available to the astronomical community. (Dr K. O. Wright)

\section{Motions of Thanks}

The thanks of the Commission were officially extended as follows:

I. For their work on the Bibliography of Eclipsing Binaries to: Mrs Kron, Mrs Merrill, and Drs Cester, Fresa, Plaut, Plavec, Sahade, Schneller and Shulberg.

2. For their work in arranging and co-ordinating observing programs, to: Drs Gyldenkerne, Sahade and K. O. Wright.

3. For their work in arranging the Joint Discussion ' $\mathrm{C}$ ' on Close Binaries to: Drs Sahade (Chairman), McLaughlin, Merrill, Petrie, van de Kamp.

4. To the members of the Organizing Committee for $1961-4$ and to the members of the Standing Committees and the ad hoc Committees who have served before and during this Assembly.

5. To Drs Batten and Merrill and to Mrs Merrill, for their work before, during, and after these sessions. 